Anuario Latinoamericano Ciencias Políticas

y Relaciones Internacionales

vol. 1, 2014

p. $17-23$

\title{
Algunas reflexiones sobre la integración latinoamericana a la luz de la integración europea
}

\author{
Antonio Colomer Viadel \\ UNIVERSIDAD POLITÉCNICA DE VALENCIA, \\ ESPAÑA \\ $\triangle$ ancovia@urb.upv.es
}

\section{RESUMEN}

En el mundo globalizado, la inserción internacional de los países de forma aislada les coloca en posición de debilidad. Por ello, existe una tendencia generalizada a las uniones regionales de Estados para fortalecer su presencia internacional. Esta tendencia se ha reforzado en los últimos años en América Latina y, especialmente, en América del Sur. Existe, sin embargo, el problema de la debilidad institucional de las organizaciones de integración así como del derecho supranacional de integración. Del mismo modo, se echa en falta organizaciones fuertes para resolver los conflictos y controversias generados en su interior. En este sentido, la experiencia de organizaciones con mayor antigüedad, como la Unión Europea, puede ser útil, pese a los problemas de la crisis actual.

PALABRAS CLAVE: integración, América Latina, Unión Europea.

\section{SUMMARY}

In the globalised world, single countries are in a more vulnerable position. For that reason, the countries tend to join regional unions in order to strengthen their international presence. Lately, in Latin America and especially South America, this tendency has been intensified. However, there is lack of powerful organizations which could settle disputes arising between their members. In this regard, we could refer to the experience of organizations with a long track record, such as, for example, European Union. In spite of the current economical crisis, it could be useful for us.

KEYWORDS: integration, Latin America, European Union.

Siempre existe un riesgo en el enfoque de "vidas paralelas", al querer acentuar las semejanzas e ignorar las diferencias. De todas formas, la mayor antigüedad del modelo integrador europeo autoriza a extraer algunas enseñanzas para procesos integradores más recientes, como el latinoamericano. Sería, sin em- 
América Latina: cambios a nivel regional y en su inserción internacional bargo, un error el mero mimetismo sin tener en cuenta la idiosincrasia propia de los pueblos, a la que deben adaptarse sus estructuras jurídicas organizativas.

Es evidente que en la Europa de posguerra mundial existían profundas diferencias de idiomas, tradiciones históricas, culturas e incluso graves conflictos entre países. Ahora bien, se daba la voluntad de superar la catástrofe histórica de la guerra y de encontrar un principio de convergencia basado en la convivencia pacífica, la cooperación y el denominador común democrático.

En principio, en América Latina podrían detectarse mayores factores de integración por la unidad del idioma, o idiomas ibéricos, la tradición cultural compartida, la religión común y las instituciones republicanas semejantes, así como un orden jurídico basado en la tradición romanista, transmitida a través del derecho español. Tampoco se habían dado conflictos tan graves y violentos como las históricas guerras en territorio europeo.

Los proyectos integradores nacen en el mismo momento de la independencia y los libertadores, como Bolívar, San Martín y otros muchos, son abanderados de esta idea que se mantiene viva incluso a nivel programático en numerosas constituciones de los países latinoamericanos (Viadel 2006). ${ }^{1}$ En la hora presente no se trata ya de grandes ideales, sino de necesidades urgentes de supervivencia en el nuevo orden internacional globalizado en el que países aislados quedan completamente marginados. Al mismo tiempo, la culminación del Estado de Derecho, social y democrático, posiblemente no pueda alcanzarse, sino en la fase de integración regional de los países latinoamericanos (Viadel 2009). La integración es una necesidad acuciante para poder insertarse globalizado con alguna capacidad de negociación efectiva y para mantener también cierta autonomía cultural y de conocimiento propia. Entre el riesgo y la esperanza se encuentra esta dialéctica (Viadel 2012a). En los últimos años, Sudamérica ha sido el lugar donde las experiencias de integración han evolucionado más. En el caso de México, este país está condicionado por su integración comercial con Canadá y EEUU, lo que afecta no sólo su realidad económica, sino su realidad social, debido a los flujos de inmigrantes mexicanos hacia los países del norte.

En el momento de detectar contradicciones entre ambos modelos podríamos señalar que las sociedades latinoamericanas están menos estructuradas, con unos graves niveles de desigualdad y con menor convencimiento democrático, dada la fuerza de las élites oligárquicas en toda su historia. También perviven factores nacionalistas que desconfían de los procesos de integración y quieren convertir una concepción mítica de la soberanía nacional en un valladar para intromisiones de los vecinos y un freno a cualquier cesión de soberanía, considerada como una forma de traición, a pesar de que esas mismas élites no tuvieron inconveniente en ceder a las presiones de organismos internacionales de carácter económico, la determinación de sus políticas

1 Véase el capítulo titulado Soberanía e integración en Iberoamérica: Una perspectiva histórica y jurídica. 
económicas y la prioridad del pago de la deuda externa, incluso a costa de las necesarias políticas sociales internas.

La integración necesita una profundización democrática compartida, así como la puesta en valor de las garantías de los derechos fundamentales de las personas, la mejora de los servicios públicos a los ciudadanos y la consolidación de la paz social y la seguridad jurídica, para lo que es imprescindible reducir las desigualdades. Este denominador común es una levadura integradora fundamental que, en buena medida, ha sido la clave para la construcción integradora en la Unión Europea y se da con más debilidad en las organizaciones de integración latinoamericana (Viadel 2007, 2012b). ${ }^{2}$

Los principios de solidaridad y cohesión social han sido básicos en la construcción europea y por medio de ellos se han cerrado poco a poco las brechas de desigualdades mediante transferencias financieras de fondos europeos a aquellos países que se incorporaban por un nivel por debajo del $90 \%$ de la renta media en la Unión Europea. Generalizar estos principios en los procesos de integración latinoamericanos nos parece muy necesario y hacerlo también desde la perspectiva del principio de subsidiariedad por el cual todo lo que pueda hacerse al nivel más próximo a los ciudadanos no debe hacerse a escala superior. Pensemos que esos fondos europeos de solidaridad se han facilitado fundamentalmente para ayudas a municipios y regiones menos desarrolladas de los diferentes países.

En el caso latinoamericano, se ha dado en 2005 la modesta institucionalización en el Fondo para la Convergencia Estructural y Fortalecimiento de la estructura institucional del MERCOSUR, que manejó unos recursos de 100 millones de dólares a partir de aportaciones de Brasil y Argentina de las que resultaban beneficiados los otros socios más pequeños, Uruguay y Paraguay. Debemos también llamar la atención en este campo sobre la peculiaridad del proyecto integrador del ALBA promovido desde Venezuela que, en gran medida, se manifestaba como un proyecto de cooperación mediante campañas de asistencia sanitaria y educativa, así como cesión de petróleo, en condiciones mucho más económicas que las del mercado, a los países con menos recursos.

El entramado institucional de los procesos latinoamericanos es, en general, débil - tal vez con la excepción de la Comunidad Andina de Naciones (CAN) - y tiene fundamentalmente un carácter intergubernamental, ya que casi no existen normas supranacionales de aplicación directa. Posiblemente, el factor del presidencialismo latinoamericano y el liderazgo de estos dirigentes nada dispuestos a ceder capacidad de decisión explican esta desconfianza hacia el mayor crecimiento institucional y a la creación de un verdadero orden jurídico supranacional lo que sí se da en la Unión Europea con el llamado

2 No podemos soslayar las dificultades presentes en la construcción europea en donde pareciera haberse debilitado el principio de solidaridad y donde las interferencias de elementos exógenos del mundo financiero especulador del carácter internacional están provocando perturbaciones y disfuncionalidades en el seno de la Unión Europea y en particular en la zona euro.
Algunas reflexiones sobre la integración latinoamericana a la luz de la integración europea

Antonio Colomer Viadel 
América Latina: cambios a nivel regional y en su inserción internacional
Derecho Comunitario Europeo. Además, el Tribunal de Justicia Europeo tiene verdadera capacidad jurisdiccional para exigir el cumplimiento de este derecho a los países integrados en la Unión. Sólo el Tribunal de Justicia de la CAN tiene alguna semejanza, aunque con una menor fuerza coactiva, y además, dado el debilitamiento de esta organización regional de los últimos años, también se han resentido sus instituciones. En el MERCOSUR, desde su fundación por el Tratado de Asunción de 1991, se tuvo que esperar más de una década para la creación del Tribunal Permanente de Revisión, para resolver controversias. Pero con la contradicción de que los países parte pueden elegir someterse a otras jurisdicciones como la de la Organización Mundial de Comercio o el Tribunal Internacional de Justicia de Naciones Unidas en la Haya. Se da la paradoja de que la solución de controversias puede hacerse fuera del entramado institucional del propio MERCOSUR.

Un acuerdo de complementación económica entre MERCOSUR y la Comunidad Andina, con el apoyo de la Asociación Latinoamericana de Integración (ALADI) ha pretendido desde hace tiempo incrementar la masa crítica institucional y ponerla también al servicio del proyecto de Comunidad Sudamericana de Naciones que nace en Cusco (Perú) en 2004 y que, finalmente, va a denominarse la Unión de Naciones Sudamericanas (UNASUR). Una vía para fortalecer la integración ha sido la de convergencia de intereses $\mathrm{y}$, en este sentido, es importante el acuerdo de los doce presidentes sudamericanos en Brasilia el año 2000 que crea la Iniciativa para la Integración de la Infraestructura Regional Sudamericana (IIRSA) y el Plan de Acción para la Integración Física Sudamericana. Prácticamente todos los países comparten la necesidad de unas mejores comunicaciones que faciliten el comercio regional y también la salida hacia el exterior, por vía terrestre, marítima, fluvial y aérea, así como las comunicaciones tecnológicas. En la misma línea, la comunicación energética mediante gasoductos para el envío de petróleo y gases desde los países productores a los no productores a cambio de otros productos de estos últimos, especialmente en alimentación.

Un último desafío es el de la integración financiera que rompa con la dependencia externa y permita un alto grado de autonomía a la región e invulnerabilidad frente a las agresiones externas de carácter especulativo. Recordemos que el proceso de integración europea nace a principio de los años 50 del siglo XX con un acuerdo inicial sobre el carbón y el acero y que la integración financiera ha llevado a la creación de una moneda única, el euro, y de un Banco Central Europeo con importantes competencias en política monetaria y financiera que permite abordar la situación de crisis de algunos países de la Unión desde una política económica y financiera solidaria. Evidentemente, en esta cooperación de infraestructuras todos están interesados, más allá de las diferencias de regímenes políticos y de contradicciones ideológicas y, por ello, hay que hacer especial énfasis en esa acción convergente común.

Posiblemente la creación de cuerpos técnicos administrativos de buena cualificación para los órganos de integración es imprescindible en el caso la- 
tinoamericano, así como la estandarización de normas dentro de cada bloque y la descentralización que permita políticas locales de cooperación intermunicipal e interregional sin tener que esperar a grandes acuerdos entre gobiernos. El impulso político es también imprescindible para que crezcan tales proyectos integradores y que las decisiones económicas y sociales se apliquen eficazmente. La lucha contra la desigualdad y la pobreza exige políticas sociales en el campo de la educación, de la sanidad, de la vivienda y también una estrategia a favor de la agroindustria que dé prioridad a la alimentación de las poblaciones y permita surgir una demanda interna como motor de crecimiento. En este sentido, la aparición y desarrollo del Parlamento Latinoamericano pareciera un instrumento adecuado para incrementar la cooperación cultural, educativa, científica e investigadora. También las Cumbres Iberoamericanas, como la número 20 que se ha celebrado los días 2 y 3 de noviembre de 2010 en Mar de Plata, han querido hacer énfasis en la creación de un fondo para la educación, aunque otros intereses estratégicos y pugnas ideológicas se interfieran.

No podemos olvidar ese $62 \%$ de la población activa latinoamericana que continúa en la economía informal y para la cual es necesaria una estrategia de integración, favoreciendo sectores de economía solidaria y cooperativa, con recursos de apoyo suficientes para poder competir con cierta igualdad con los otros sectores público y privado.

La Corte Interamericana de Derechos Humanos, con sede en San José (Costa Rica), debería tener más fuerza, disponer de más medios y una mayor eficacia en la aplicación de su jurisprudencia. El caso del Tribunal Europeo de Derechos Humanos debe tenerse en cuenta en su capacidad de sancionar a países europeos en esta materia. Del mismo modo, el Tribunal Europeo de Justicia interpreta los Tratados y reglas del Derecho Comunitario y soluciona los conflictos o incumplimientos de esta normativa. Este es un instrumento fundamental en un proceso de integración que quiera tener solidez.

La pugna ideológica entre el Proyecto ALCA - inspirado como acuerdo de libre comercio por Estados Unidos y que finalmente naufragó en la reunión de Mar de Plata de 2005 - y el proyecto ALBA, movido por Venezuela como contrapunto al primero, pero de carácter político y de naturaleza ideológica socialista, debiera decantarse hacia una autonomía de la región en la que pudieran convivir en una integración multilateral con regímenes políticos diferentes, pero que compartan una identidad histórica común y una voluntad de cooperación de interés recíproco. Ese proyecto debe estar al servicio de una nueva estrategia de cohesión social y una autonomía para negociar con libertad en el orden internacional. En este sentido, los acuerdos con la Unión Europea que ha actuado como "un federador externo" de América Latina porque en todos sus acuerdos ha establecido la condición de mantener el entramado integrador, puede dar lugar a una asociación estratégica, pero que no cierre a América Latina la posibilidad de otros acuerdos con diferentes regiones del mundo.

La integración es un camino sin retorno, si América Latina no quiere ser arrojada a una zanja de la historia. Diferentes desafíos tienen que ser asumi-
Algunas reflexiones sobre la integración latinoamericana a la luz de la integración europea

Antonio Colomer Viadel 
América Latina: cambios a nivel regional y en su inserción internacional dos. Los proyectos de integración física y de comunicaciones son una levadura de integración eficaz y rápida, pero en ellos también hay que favorecer la transparencia y la lucha contra la corrupción que es otro desafío generalizado. La cooperación en energía y sistema financiero también se presentan como factor de integración de una gran importancia y el Banco del Sur una herramienta eficaz para ello. La integración del conocimiento mediante proyectos compartidos de $\mathrm{I}+\mathrm{D}+\mathrm{I}$ (investigación, desarrollo, innovación) es una exigencia de nuestra época. La mejora de la masa crítica institucional de las organizaciones de integración y la convergencia entre ellas es imprescindible. La mayor densidad del orden normativo y que algunas reglas tengan carácter supranacional que se impongan a los órdenes jurídicos internos es imprescindible como demuestra la experiencia europea. También es necesario la creación y el fortalecimiento de instituciones de solución de controversias con capacidad vinculante y autoridad aceptada por todos.

Ya dijimos que la integración puede empezar desde abajo a través de la descentralización de municipios y regiones y los acuerdos intermunicipales e interregionales. La solidaridad y la cohesión social son mandatos imprescindibles no sólo de carácter gubernamental sino a través de las organizaciones comunitarias de la sociedad civil y en la lucha contra la pobreza y la desigualdad. La complementariedad económica debe dar prioridad a la agroindustria, abasteciendo de alimentos a las poblaciones y promoviendo la demanda interna mediante el intercambio interregional que elimine intermediarios e incluso signos monetarios en los mismos.

Las garantías de defensa jurídica ante abusos de poder o violación de la ley y de los derechos fundamentales de las personas es objetivo irrenunciable y fundamental y, para ello, se hace imprescindible una selección objetiva y transparente de los miembros del poder judicial que respondan a la triple I: Independencia, Imparcialidad, Integridad. Hay que reconvertir la Corte Interamericana de Derechos Humanos para que tenga un plan de actuación autónomo para el mundo iberoamericano, sin dependencias externas y, además, fortalecer su estructura y exigir el estricto cumplimiento de sus sentencias y autos.

Una estructura de integración es más que un acuerdo comercial. Debe responder a valores y ética social inspiradores de lucha contra las desigualdades, de consenso social y respeto al pluralismo político de regeneración democrática. Debe combinar elementos distantes para encontrar su punto de equilibrio mediante imaginación y tolerancia recíproca que combine intereses compartidos e ideales básicos sobre la dignidad del hombre y su papel en la sociedad. Sólo así el proyecto integrador, tan necesario para sobrevivir en este mundo globalizado, no se frustrará. 


\section{Bibliografía}

Colomer Viadel A. (2006), Constitución, Estado y Democracia en el Siglo XXI, Editorial UPV, Valencia.

Colomer Viadel A. (2007), (coord.), La integración política en Europa y en América Latina, Editorial UGARIT, Valencia.

Colomer Viadel A. (2009), Introducción al Constitucionalismo Iberoamericano, 2a ed., Editorial Trillas, México D.F.

Colomer Viadel A. (2012a), (ed.), América Latina, globalidad e integración, Vol. I, Editorial Del Orto, Madrid.

Colomer Viadel A. (2012b), (coord.), Un nuevo rapto de Europa. Las encrucijadas del Tratado de Lisboa, Editorial HATHI e IBEM, Valencia.
Algunas reflexiones sobre la integración latinoamericana a la luz de la integración europea

Antonio Colomer Viadel 